\title{
Attitudes Toward Code-switching in a Saudi Public Hospital
}

\author{
Maram Nasser Alzeer
}

English Department, King Saud University, Riyadh, Saudi Arabia 


\begin{abstract}
The study was conducted at King Khalid University Hospital (KKUH) - a multilingual and multicultural environment-because of the different nationalities and backgrounds of the medical staff working there. These differences created the likelihood that code-switching (CS) would occur between the spoken dialects and languages. This study investigated the attitudes of the medical staff toward CS between Arabic and English as they were the most spoken languages in the hospitals. To achieve its aim, the study adopted a mixed-methods approach. It distributed 64 questionnaires among the medical staff working at three units in the hospital and interviewed seven members. The qualitative and quantitative data showed that the majority of the staff expressed positive attitudes toward the practice in the hospital. However, almost all of them expressed negative attitudes toward CS during a medical discussion. The variables that had an effect on attitudes towards CS were the nationality (linguistic background), and social status. However, age and gender were not found to be influential social variables, as both females and males as well as young and old participants expressed similar attitudes. These findings suggest several courses of action for hospital administrations and designers of preparatory courses.
\end{abstract}




\section{Introduction}

Sociolinguistic phenomena are created when bilinguals or multi-linguals interact and move from one language to another. One of those phenomena is called code-switching (CS). CS can be investigated from three perspectives: the grammatical approach, the psycholinguistic approach, and the sociolinguistic approach (Bullock \& Toribio, 2009). This study adopted the sociolinguistic approach, as it is concerned with the attitudes towards CS and influencing social factors (e.g. age, gender, and social status). In Saudi Arabia (SA), the healthcare sector is multilingual and multicultural. Achieving successful communication in this context is crucial because of the delicate nature of the healthcare context that requires accurate delivery of information. This accuracy must be achieved between the medical staff and the patients, as well as between the members of the medical staff. Communication patterns between medical staff members with patients have been investigated by Belaskri (2017), De Socarraz-Novoa (2015), Nur'Aini \& Fanani (2019), Odebunmi (2013), and Singo (2014). However, the attiutdes of the medical staff members towards CS, like attiudes towards CS during interaction between doctors and nurses was given little attention, especially in terms of Arabic-English CS.

\section{Aim and Significance}

To date and as far as the researcher knows, Alhamami (2019) is the only study who have investigated this attitudes towards CS in the non-academic Saudi healthcare sector. However, his investigations of CS were limited to public healthcare in the Makkah region and to the use of qualitative measures of research. Therefore, this study aims to fill a gap in the literature by investigating the attitudes towards CS phenomenon in a public hospital in Riyadh using qualitative and quantitative measures. Riyadh is culturally and linguistically distinct from Makkah (AbdulSalam 
et al., 2014). With its location being in the center of the country, it was less exposed to foreign languages, including English. However, with the development of technology and King Salman's Saudi Vision 2030 (Kindom of Saudi Arabia, 2020), Riyadh is becoming more open to other languages and cultures. Therefore, investigating a different region would contribute to sociolinguistic research by describing the current English language status and by helping to provide a better understanding of Arabic-English CS in Saudi Arabia through understanding the attitudes towards it. This understanding of the sociolinguistic situation helps vocational preparation courses like English for medical purposes and language programs to provide training based on actual situations. This may produce more efficient employees who can communicate with each other to serve patients. Moreover, understanding the current Arabic-English CS state would help hospital administrations recognize the situation and provide more linguistic assistance for visitors and employees where needed.

\section{Literature review}

Attitude can be defined as "a disposition to react favorably or unfavorably to a class of objects" (Sarnoff, 1970, p. 279, as cited in Garrett, 2010). This means that attitudes are not innate; people are not born with certain feelings toward objects and ideas (Garrett, 2010). In fact, these feelings come from the surrounding environment, like society and family members, and from cultural values (Holmes, 2013). It also means that feelings are not temporary. Rather, they are stable, and they develop over time and require time to change (Garrett, 2010). The class of social objects refers to anything from a language or a government policy or rule, to a social phenomenon like CS (Garrett, 2010). Finally, feelings also have an evaluative nature in the sense that they can be negative or positive (Dewaele \& Wei, 2014). 
Therefore, attitudes toward CS can be negative or positive. Code-switching is often cited in a negative way; it is seen as a sign of "impurity" coming from ideologies supporting monolingualism, where one language should be spoken at a time (Dewaele \& Wei, 2014). This is more prominent in former colonies like Morocco or in colonizer countries like the United Kingdom, where CS might be viewed as gibberish (Holmes, 2013). It is also viewed as a sign of "laziness" or "linguistic incompetence" among bilinguals, though in bilingual or multilingual situations, it can be used as a powerful communicative strategy to identify one's social identity and solidarity to a certain community (Garrett, 2010). On the other hand, positive attitudes toward CS stem from showing solidarity to a certain social group that uses that language, showing pride in the ethnic identity" (Holmes, 2013). Attitudes, whether positive or negative, influence the production and perception of language — what code to use and why (Garrett, 2010). Moreover, attitudes are influenced by socio-biographical factors like education, gender, and age, and by variables like personality and history of linguistic practice (Dewaele \& Wei, 2014).

A rich literature exists documenting investigations of CS in academic contexts and bilingual children's language acquisition (Dewaele \& Wei, 2014). Earlier studies reported negative attitudes toward the phenomenon, attributing it to linguistic deficiency by the learner or poor judgment of linguistic choice made by the child (Dewaele \& Wei, 2014). However, recent studies have reported more positive attitudes toward the phenomenon for use as an effective teaching strategy (e.g. Canagarajah, 2011). It is also seen as a sign of linguistic development with a high level of linguistic creativity (e.g. Wei, 2011). In addition, most of the studies focused on attitudes toward CS in academic contexts where its use was restricted, as in foreign or second language teaching classrooms (Dewaele \& Wei, 2014). This can also be 
found in Arabic-English CS contexts, where attitudes toward the phenomenon are investigated in academic contexts.

For example, in Abha, Al Asmari (2014) investigated the attitudes of 100 PYP teachers of both genders toward CS and using Arabic in their EFL classrooms. The researcher adopted qualitative methods, distributing questionnaires with 22 Likertscale items that aimed at identifying the teachers' opinions toward the use of Arabic in their classes. The results revealed that both groups reported positive attitudes toward the use of their mother tongue and viewed its use as an effective teaching technique. Similarly, Shuchi and Islam (2016) investigated the use of the mother tongue among university students and teachers, Arabic in Abha and Jazan and Begladishi in Dhaka. The study adopted an embedded mixed approach by using two types of questionnaires to collect qualitative and quantitative data. The results showed that both the teachers and students supported the mixed use of the mother tongue with English to facilitate communication.

Likewise, Alenezi (2016) investigated the attitudes of medical students toward CS at Northern Border University and the influence of gender on those attitudes. The data were collected through questionnaires distributed among 189 students. The results revealed no significant difference between the attitudes of female and male students as both genders expressed positive attitudes toward the use of CS in their classes, noting that it helped them to understand the courses.

In another study, in Riyadh, Omar and Ilyas (2018) studied Saudi academics’ attitudes toward Arabic-English CS. The participants were 10 instructors and 40 students from the preparatory year program (PYP). The study adopted a qualitative approach to the investigation, using interviews and focused group discussions for data collection. The data were analyzed through content analysis techniques to identify 
reasons for CS and attitudes toward it. Irrespective of variables like age, gender, and education, the results revealed that there was a symmetrical relationship between age, level of education, and CS. Young university participants had positive attitudes toward CS. It was found that CS was used to hide low levels of English language proficiency or to identify with a group member (the elite), native speakers of the foreign language, or with one's culture and ethnicity ("we-code" and "they-code"), facilitating interpersonal relations.

Similarly, Almohaimeed and Almurshed (2018) investigated Saudi PYP students' attitudes toward CS in the classrooms. Gaebler's questionnaire (2014) was distributed to 60 female students with different levels of English proficiency. The results revealed negative attitudes toward CS among high-level students and positive attitudes among students at lower levels. Likewise, Alkhawaldeh (2019) investigated the phenomenon among 70 female university students using questionnaires. The majority reported positive attitudes toward CS as a sign for higher qualification and rank, while those who revealed negative attitudes attributed CS to its diglossic roots, where each code should be restricted for use in one situation.

With a slightly different focus, Al-Qahtani (2014) investigated CS as a strategy for communication in an academic context both in and outside the classroom. He studied 18 faculty members working at the College of Language and Translation at King Khalid University, Saudi Arabia. The participants were of different nationalities, including Arab, American, Indian/Pakistani, South African, and Romanian. He adopted qualitative methods of research using observation and conducting two-session interviews. The majority revealed positive attitudes toward $\mathrm{CS}$ in the classroom context, as compensation for language incompetence, and as an effective strategy for communication. However, the Romanians believed that CS can 
be used for social functions like gaining approval, impressing the interlocutors, and complimenting the other in classrooms. However, only the Romanians showed positive attitudes, while other nationalities showed negative attitudes toward its usage. It should be noted that all participants used both codes in their classrooms, regardless of their attitudes. The majority showed positive attitudes toward CS and its benefits in social gatherings and the workplace. "They all agree that it promotes social interaction; compliments other members of other cultures; signifies in-group membership, be it professional, cultural or even religious group" (Al-Qahtani, 2014, p. 7). It should be noted that the Arabs showed negative attitudes toward CS with other Arabs, stemming from the ideology of one situation.

Studies on the attitudes toward English CS in the workplace presented here are in the context of the Asian and Arab region because only one study specifically addressed attitudes toward CS in a Saudi context. For example, in Jordan, Hleihil (2001) investigated CS motivations and attitudes in fast-food restaurants in three major cities in Jordan: Amman, Zarqa, and Irbid. The sample included 200 participants, including costumers and salespersons. A quantitative method of analysis was conducted using data gathered from a 28-item questionnaire. Gender, age, occupation, and region were the independent variables. The results revealed positive attitudes toward CS as a communication strategy, and they also denied the relationship between CS and the appearance of a high level of education. It was also noted that the more educated the participant was, the more accepting of CS he or she was. Most interestingly, the cities of Zarqa and Irbid showed negative attitudes toward CS to discuss work matters, while participants in Amman, the capital city, showed positive attitudes. This result was attributed to the higher level of education of the 
customers in the capital city, which provides better education and better socioeconomic conditions.

In another study in Jordan, Al Matarneh (2011) investigated Arabic-English CS among aviation personnel at the Amman civil airport and their attitudes toward the phenomenon. He used a mixed-methods research approach, using both questionnaires and interviews. The sample comprised 200 participants, 10 of whom were randomly selected for the interviews. The questionnaire data analysis revealed that most of the personnel had positive attitudes toward the phenomenon as a strategy for communication and getting the job done. The results of the interview analysis supported the questionnaire findings.

In Saudi Arabia, Alhamami (2019) analyzed code variation and attitudes toward CS at a public hospital in the Makkah Province. The study sample was selectively chosen to represent the multicultural and multilingual environment of the hospital. The sample included patients and medical and non-medical hospital staff. Semi-structured interviews were the primary method for data collection. The results showed that most occasions involving the use of CS were viewed positively, as they helped to create effective communication. The only negative attitudes were created because of feelings of neglect and isolation among the patients and feelings of concealment and disrespect among colleagues.

From these studies, we can conclude that Saudi EFL/learners and teachers in academic settings are developing positive attitudes toward CS. However, traces of negative attitudes stemming from the ideology of monolingualist purity with the use of one code in one situation remain. Nonetheless, no matter what the attitude is, it seems that CS was still practiced in the Saudi EFL academic contexts. Moreover, the level of education was the variable that most influenced CS in the Saudi Arabian 
academic context. Likewise, the attitudes toward CS in the institutional workplace environment were mostly positive; they aimed at getting the job done efficiently and expressing a prestigious air to the speakers. On the other hand, the regional variable had more influence on using CS in institutional workplace settings (Hleihil, 2001).

\section{Methodology}

The investigation adopted a mixed-methods approach, as using quantitative and qualitative methods allows for more in-depth analysis and increases the reliability of the results (Dörnyei, 2007). A mixed-methods approach also allows for the triangulation of the data, provides a fuller understanding of the phenomenon, validates one set of results against another, and generates access to a wider range of the sample population (Dörnyei, 2007). For example, the collected data from the questionnaire filled by the lab specialists helped in presenting a full description of the environment in the Microbiology unit.

\section{Research Questions}

In order to fulfil the aim of the study, the researcher asked the following questions:

1- What are the attitudes toward code-switching among the medical staff at KKUH?

2- Does sociolinguistic variables (e.g. age, gender, social status and nationality (linguistic background)) influence the medical staff attitudes towards CS?

The research questions investigated the attitudes of the medical staff toward the phenomenon, including how the participants felt about CS in the hospital in general, as well as its use for medical and social purposes. Attitudes toward the use of CS influence the participants' choice of code; thus, understanding the staff's feelings 
about CS provided a further understanding of the phenomenon in the hospital. Data from semi-structured interviews and questionnaires were used to answer this question.

\section{The Context of the Study and Participants}

The study was conducted at KKUH in Riyadh, Saudi Arabia. KKUH operates in the King Saud University Medical City's network. It also provides training for students from the University's College of Medicine. The hospital has been operating for decades, and it provides general and subspecialty medical services. The present study was conducted in three specific departments, namely the one day surgery unit (DOS), the medical day care unit (MDU), and the microbiology unit in the pathology department (Micro). Both the hospital and the departments were selected because of the researcher's familiarity with some of the staff, which facilitated the data collection.

Different sample sizes were recruited for each type of data. For the quantitative data, approximately 64 questionnaires were distributed randomly to the hospital staff working in the selected departments. This sample size is in line with that of Al Heeti and Al Abdely (2016). For the qualitative data, seven participants were recruited for the semi-structures interview. They included three doctors, three nurses and a lab specialist. The inclusion criteria were participants working at the selected hospital who spoke either Arabic or English or both languages. Information about age, gender, occupation, nationality, and social distance between the participants and the addressees was collected, as those factors are relevant variables that influence CS in the workplace. Other information, such as experience working in the sector, and level of education may also influence CS, but those factors were outside the scope of the study. 


\section{Research Tools}

\section{Semi-structured Interviews}

This study used semi-structured interviews to investigate attitudes toward the CS from the perspectives of the participants. The interviews were conducted in a single session that lasted approximately 10 to 15 minutes for each participant except for the interview with N8, which lasted for 20 minutes.

Semi-structured interviews are guided by a prepared schedule, but they allow the interviewer to ask follow-up questions for further elaboration and clarification (Dörnyei, 2007). The researcher adapted the interview schedule designed by Almathkuri (2017). The interview was divided into two parts, and it was designed to progress from general information to more personal, context-specific information. After building rapport and explaining the participants' rights, the researcher asked the participants about their use of CS at the hospital, The second part investigated the participants' attitudes toward CS and. In that part, the researcher asked the interviewees to describe specific CS incidents, following the approach by Almathkuri (2017). It should be noted that the wording of the questions is crucial to provide more fulfilling answers. Yes/no questions yield short and expandable answers, while exploratory questions are more likely to produce more detailed answers and to provide more options to ask for further information. If the interviewer must use direct questions, these should be followed by a tag question, such as "what else?" (Hoffmann, 2014; Tagliamonte, 2006).

After writing the schedule, conducting a pilot study is recommended to test the recording equipment for clarity, to examine the productiveness of the interview schedule, and to accustom the interviewee and the researcher to the process, as advised by Bell (2014) and by Hoffmann (2014). Only two interviews were conducted 
face to face. The other five were conducted by telephone using social network applications because of the restrictions from the COVID-19 pandemic. Those restrictions prevented the researcher from meeting with the participants. The telephone interviews were recorded using the highly rated application Call and Voice Recorder Pro. The issue of the observer's paradox was addressed by attempting to create a rapport with the interviewee, such as determining the language with which the interviewee was more comfortable.

\section{Questionnaire}

The questionnaire designed by Dewaele and Wei (2014) was adapted to serve the aim of the study and to answer research questions. Sections one and two of the questionnaire were adapted to collect demographic information and to investigate the staff's attitudes toward CS in the hospital context. Section one included information about the participants' job titles, genders, and linguistic background. Section two was adapted to include the five items that investigated attitudes, while the items pertaining to personality traits were deleted. The questionnaire was written in simple English to allow medical staff with limited English to complete it, and it was validated by three experts: two doctors and a researcher.

Schleef (2014) recommended conducting a pilot survey in which the questionnaire is distributed to a few participants who are asked to assess the questionnaire to increase its reliability and validity. The points to consider included the sufficiency and clarity of instruction, the answerability of the questions as intended by the study, the appropriateness of the length of the questionnaire, and the applicability of the data elicited for analysis. Therefore, the questionnaire underwent a pilot study. It was distributed to 30 members of the medical staff at a public hospital 
in Riyadh. The questionnaires were distributed by hand and electronically using Survey Monkey because of the COVID-19 pandemic restrictions.

\section{Generating Qualitative and Quantitative Data Results}

For the qualitative data, the transcribed interview data regarding the participants' feelings about CS were uploaded to MaxQDA. The data were categorized according to themes that expressed the participants' attitudes toward CS. The themes were coded as being positive attitudes, neutral attitudes, or negative attitudes. Interviews were also used to collect data concerning participants' attitudes toward CS by Al Matarneh (2011), Al-Qahtani (2014), Omar and Ilyas (2018), and Alhamami (2019).

For the qualitative data, a total of 64 questionnaires were collected. However, seven participants were eliminated as they were not working in the allocated units. Quantitative data collected from the questionnaire was processed using SPSS. The frequency and percentages were calculated first to provide background information about the participants (nationalities, age, gender, and social status). A combination of descriptive and inferential statistics were then used to determine the attitudes toward the practice, both in general and in relation to age, gender, and social status. This includes descriptive tests for frequency, mean, and standard deviation, and more inferential statistics such as chia square, t-test, ANOVA, and correlations.

To perform further statistical calculations, the recording of second and third statements (which express negative values) needed to be acquainted with the other three positive statements. They were recoded as in Table 1 while the other three remained as originally coded moving from 1 for strongly disagree to 5 for strongly agree. 
Table 1 Recoded values of negative statements

\begin{tabular}{|l|c|}
\hline \multicolumn{1}{|c|}{ Answer } & New code \\
\hline Strongly disagree & 5 \\
\hline Disagree & 4 \\
\hline Neutral & 3 \\
\hline Agree & 2 \\
\hline Strongly agree & 1 \\
\hline
\end{tabular}

The reliability was tested for the five items, in three turns by Cronbach's alpha. The results showed that the data were reliable with 0.285 with all 5 items. 0.404 after deleting item no. 2 and 0.604 . after deleting item no. 3 . These procedures enabled the researcher to transform the three items (positive variable) into one variable, named (attitudes-positive). The remaining two variables were tested by Cronbach's alpha to be transformed into one variable named (attitudes-negative). The results showed that the data were reliable with alpha 0.6. Then the mean and standard deviation were calculated for each item to determine the frequency of each attitude. Then ANOVA and t-test were calculated for the variables (functions, attitudespositive, and attitudes-negative) and the social variables (age, nationality, gender, and social status) to determine out the influence of those social variables on CS functions and attitudes toward it.

Statistical analyses to calculate the attitudes toward CS were used by Alhassoun (2014), Al-Khatib and Sabbah (2008), and Mahdi and Almalki (2019) in their research on CS. Al Asmari (2014), Dewaele and Wei (2014), and Almohaimeed and Almurshed (2018) used statistical analyses to study attitudes, while Hleihil (2001) used them to research both aspects.

\section{Research Ethics}

Ethical approval is necessary whenever human participants are involved (Hoffmann, 2014). Thus, the researcher obtained clearance from the research ethics 
committee at King Saud University. The same application form and a letter from the university granting ethical approval, as well as the research tools and a copy of the proposal, were then given to the research centers at KKUH and to King Saud Medical City (KSMC) to request permission to conduct the study. The researcher was told that the university's ethical approval should be sufficient to carry out the study at KKUH, but she was provided with another letter of approval from KSMC. However, because of the restrictions from the COVID-19 pandemic, data were collected from KKUH only (see Appendix A for the research ethics committees' letters of consent).

Accordingly, the purpose of the study, what participation involved (such as the period of recorded interviews), and how the data were to be used and stored were explained to the participants before conducting the study. The prospective participants were given the opportunity to ask questions, and they were asked to sign a consent form if they were interested in participating. They were informed that they had the right to withdraw from the study without explanation at any point. The data were kept anonymous when possible. However, because of the nature of qualitative research, there were some occasions on which some personal data were collected. For example, because of the restrictions from COVID-19, the researcher asked for the participants' contact information to conduct the interviews. However, it should be noted that the data were coded numerically to ensure confidentiality and anonymity.

\section{Results and Discussion}

\section{Qualitative Analysis: Staff's Attitude toward CS}

Attitudes toward CS influence how the phenomenon is practiced (Garrett, 2010). Investigating the attitudes of the medical staff toward CS in the hospital is part of understanding how the phenomenon was used there. The answers to interview were analyzed to determine staff attitudes toward using CS at the hospital. The interview 
was divided into three parts. Part one addressed the staff's general attitude toward the phenomenon as it occurred in the hospital. Part two addressed the staff's attitude toward CS to discuss medical topics. Part three addressed the staff's attitude toward CS to engage in social conversations. The analysis of the interviews showed that most of the members had positive attitudes toward this phenomenon. The result of each part is presented in the next section.

\section{General Attitudes toward CS in the Hospital}

The results for part one showed that two doctors and two nurses of the seven respondents held positive attitudes toward CS in the hospital. All four of those respondents believed that they should switch to English to discuss medical or workrelated topics and reserve Arabic for socializing. One senior member expressed the firm opinion that using CS in the hospital was the normal and proper practice in the institution, “هذا إلي صاير وهو المفروض الإنجلش للمديكال و العربي للسو اليف أصلا" (D13 interview). However, the majority were generally positive that CS can be necessary in some situations. Two of the seven members were more neutral toward the phenomenon. One believed that it was a matter of personal freedom. The senior doctor, on the other hand, conditioned his neutral opinion about CS with the majority's willingness to switch codes, “لأس بالخلط بين اللغتين طالما أن الأغلبية لا تمانع" (D7 interview). Only one member of the medical staff expressed a negative attitude toward the phenomenon. This was a Filipino nurse who felt that code-switching was confusing as she sometimes did not understand what the group was talking about. yes, I feel confusing, but first, I'm interested, I feel confusing because sometimes I really don't understand the topic, so it's very confusing, but it's fine, yes, because I'm trusting to the group, so it's OK (N6 interview). 
From the responses to part one, it can be concluded that most of the Arabicspeaking medical staff had positive or neutral attitudes toward the phenomenon, while some foreign members of the medical staff expressed somewhat negative attitudes as they found the practice confusing.

\section{Staff Attitudes toward Switching to English for Medical Topics}

The results for part two three indicated that almost all the staff members expressed positive attitudes toward the switch from Arabic to English to discuss medical topics. Only one member expressed the more neutral opinion that he supported whatever means communicated accurate information, in D7 interview, he said, “أنا لا أمانع إذا كانت المعلومة تصل بشكل صحيح ويفهها الجميع". The others believed that the switch to English was the obvious code for delivering medical information. This was because of their coursework (which was conducted in English) and the fact that English is understood by all members of the medical staff. According to D12 interview, كلام منطقي لأن أغلب المصطلحات وتعاملنا بالإنجليزي و المو اد و الأدوات الي نستخدمها بالإنجليزي، محد" "أصلا بعض الأشياء ما نعرفها بالعربي فلازم According to D13 interview . ما فيه أحد يعرفها بالعربي" نستخدم إنجليزي"

Therefore, the responses to part two indicated that most of the medical staff had positive or neutral attitudes toward the switch from Arabic to English CS to discuss medical topics. However, it should be noted that they expressed negative attitudes toward switching to Arabic while discussing medical topics; they believed English was the appropriate code for medical discussions.

\section{Staff Attitudes toward Switching to Arabic for Social Purposes}

The responses to part three were similar to those for part one. Four out of seven members expressed positive attitudes toward the switch to Arabic to socialize. The majority believed that switching to Arabic to socialize was more appropriate, 
especially if the conversation did not include a non-Arabic speaker. This was also based on the fact that Arabic is the official language in the country and it is understood by most people. One senior doctor (D13) emphasized that Arabic was more useful than English for expressing her opinions because of the level of her linguistic competence.

$$
\text { "السو اليف بالعربي، لأن أنا بالنسبة لي ما عندي لغة إني أقعد أسولف معها بإسهاب زي اللغة العربية : بالنسبة لي لأني ما راح أقدر قو ديب فور إت ما راح أقدر أقول إلي في خاطري كله راح تكون جمل ما تعبر" }
$$

(D13 interview).

The younger generation, on the other hand, believed it was more a matter of taking pride in using the mother tongue than linguistic competence: according to D12 interview, لا الحمد لله لغتي ممتازة نسبيا فقط أنه بعض الأحيان نستخدم الإنجليزية للتعبير عم بعض المصطلحات" الي مثلا عامية "سلانق" و إذا أنت عربي و انا عربي فأفضل اني أحثلك باللغة العربية الي هي لغتاك حتى أنت" According to N8 interview, she said, “لأنها لغنتا الأم ولازم ما تتدثر”.

However, the foreign member expressed positive attitudes toward the switch to English for social purposes as a more expressive language. She said, "In English, yes, it's very much good. At least you can express it in heart and you can feel it also by using the international language, English" (N6 interview). However, she also expressed neutral attitudes toward casual conversations in Arabic among the Arab members. She believed it was part of showing respect and that she could understand the gist of the topic from the body language:

It's fine but since we are in the group, we have to respect and feel comfortable, try to use all your sense to understand even if you not understanding what they are talking, but we can see in their body language their emotions, their faces so you have to feel it. what they are doing" (N6 interview). 
Thus, it can be said that five out of seven members expressed positive attitudes toward CS regardless of the switched-to code they believed was appropriate.

Two of the medical staff expressed neutral attitudes toward using Arabic to socialize. One expressed his preference for using Arabic to socialize, but he also did not mind using English, " أنا أفضل اللغة العربية ولكن لا بأس باستخدام اللغة الأنجليزية في التحية أو العزاء، (D7 interview). The other younger member did not express any preference. She did فيه " not think about what language she used as long as it communicated her meaning (lab "ناس في المستشفى يحسون أنها كثخة بس أنا عادي، حتى مو من النوع الي يتمسك باستخدام اللغة العربية، عادي specialist interview).

According to the responses to part three, it can be concluded that most of the medical staff expressed positive or neutral attitudes toward the phenomenon.

In summary, the interview responses reported that most of the young Arab medical staff (D12, N1, and N8) had positive attitudes toward code-switching. The senior Arab members (D13 and D7) expressed positive and neutral attitudes. This can be attributed to the environment where and who they work with. According to the researcher's field notes, D13 did not interact with foreign members of the staff as much as D7, who interacted with them in critical environments such as the OR. He was more concerned with delivering accurate information through whatever means worked. The lab specialist also worked in a critical environment with many foreign workers from different nationalities: Pakistanis, Indians, and Filipinos. She was more concerned with getting the job done as quickly as possible. Finally, a foreign member of the medical staff reported mixed attitudes. She did not appreciate the phenomenon of CS as an idea. However, in practice, she expressed positive and neutral attitudes particularly in situations where she was involved in a group conversation. The overall positive attitudes toward CS in professional contexts also was reported in the 
literature. For example, some studies in academic contexts reported that more participants expressed positive attitudes toward CS in the classrooms than those who expressed negative attitudes (Al-Qahtani, 2014; Alkhawaldeh, 2019; Almohaimeed \& Almurshed, 2018; Asmari, 2014). In the workplace contexts, both Al Matarneh (2011) and Hleihil (2001) reported more positive attitudes toward CS in urban cities of Jordan. Finally, in the medical context, Alhamami (2019) reported that positive attitudes were more common about using CS in hospitals in Saudi Arabia.

\section{Factors Influencing the Staff Attitudes toward CS}

The results of the interviews showed that the two most influential factors were the social status, and linguistic background. Age and gender were not significantly influential variables; both young and senior and male and female members expressed similar attitudes toward CS. Moreover, participants of similar age in other studies reported similar results. For instance, Shuchi and Islam (2016) found that both teachers and university students expressed positive attitudes toward CS in the classroom. Likewise, gender was not reported to be a significant variable for attitudes toward CS in a professional context. This is consistent with findings by Asmari (2014) and Omar and Ilyas (2018) that instructors of both genders expressed positive attitudes toward CS. However, Omar and Ilyas (2018) noted that female instructors switched codes in social networks more than their male colleagues despite both genders having similar positive attitudes.

The results showed that nationality (linguistic background) and social status were influential factors. The social status as an influencing factor was consistent with other studies. Al-Qahtani (2014) reported that Arab faculty members expressed mixed attitudes toward CS, depending on the audience and their linguistic background. They expressed positive attitudes toward CS in their classrooms and for their students, or 
outside the classroom to socialize with foreign faculty members. However, they expressed negative attitudes toward CS when socializing with Arab faculty members in an interaction that did not include foreign colleagues. Likewise, Almathkuri (2017) reported that a Pakistani doctor favored CS, as he usually works with a Saudi nurse who was not a competent user of English. On the other hand, he also reported that a Saudi doctor did not favor CS to discuss medical matters, as he usually works with a Filipino nurse who is more competent in English than in Arabic. As for social status, Alhamami (2019) reported that while doctors and nurses expressed positive attitudes toward CS in the hospital, visitors reported negative attitudes toward CS.

Nationality (linguistic background) also was reported to be an influential factor both with foreign members whose English and Arabic were not their native languages and native Arab members who spoke English as a foreign language. The literature reported mixed results for foreign speakers' attitudes. Both Al-Qahtani (2014) and Almathkuri (2017) reported that foreign members expressed positive attitudes toward CS in their work and social contexts. On the other hand, Alhamami (2019) noted that some foreign staff members expressed negative attitudes based on feeling neglected or disrespected when their colleagues switched to Arabic. The results showed that linguistic background influenced the attitudes of members who were not competent speakers. They expressed more positive attitudes toward CS. N8 and D13 explicitly stated that they preferred to switch when they found their English was lacking. This was also reported in other studies (Almohaimeed \& Almurshed, 2018; Omar \& Ilyas, 2018; Shuchi \& Islam, 2016).

In conclusion, the results of the interview analysis showed that most of the medical staff expressed positive attitudes toward CS in the hospital. They preferred to switch to English to discuss medical topics and to Arabic to socialize. Age and gender 
were not influential factors, as both older and younger and both male and female members expressed similar attitudes. On the other hand, it was reported that social status, nationality (linguistic background) were influential factors.

\section{Quantitative Analysis: Staff's Attitude toward CS}

\section{Statistical Tests for Positive Attitudes}

The mean of all the positive attitude variables combined was 3.3 on the 5point scale, which is above the medium level. This means that most of the participants reported positive attitudes toward CS in the hospital. The means for the other categories are in Table 4, as are the frequencies and percentages of responses.

Friedman Test Chi-Square showed a significant order of difference for these three positive attitude variables, $\chi^{2}(2)=27.722$, with a high level of significance $(p=$ .0001). Most of the participants expressed positive attitudes toward CS because switching between Arabic and English in conversations was a useful means to get the job done and to communicate $(\mathrm{M}=3.9, S D=0.83)$. This attitude was considered to be at a high level, and the standard deviation was small (less than 1). The second reason that the staff expressed positive attitudes was that "Switching between Arabic and English in conversations displayed a distinct multicultural identity such as my identity as a highly educated doctor or a nurse and my identity as an Arab" $(\mathrm{M}=3.16, S D=$ 1.2). The least reported reason for the positive attitude was "Switching between Arabic and English in conversations is a way to show solidarity with culture such as my solidarity with the Islamic or the Saudi culture" $(\mathrm{M}=2.95, S D=1.2)$.

Expressing positive attitudes toward CS was also reported in a number of studies (e.g., Al-Qahtani, 2014; Al Matarneh, 2011; Alhamami, 2019; Alkhawaldeh, 2019; Asmari, 2014; Hleihil, 2001; Omar \& Ilyas, 2018; Shuchi \& Islam, 2016). 
Table 2 Positive Attitudes toward switching between Arabic and English

\begin{tabular}{|c|c|c|c|c|c|c|c|c|c|c|c|c|}
\hline \multirow{3}{*}{ Code } & \multicolumn{2}{|c|}{$\begin{array}{l}\text { Strongly } \\
\text { disagree }\end{array}$} & \multicolumn{2}{|c|}{ Disagree } & \multicolumn{2}{|c|}{ Neutral } & \multicolumn{2}{|c|}{ Agree } & \multicolumn{2}{|c|}{$\begin{array}{c}\text { Strongly } \\
\text { agree }\end{array}$} & & \\
\hline & \multicolumn{2}{|r|}{1} & \multicolumn{2}{|c|}{2} & \multicolumn{2}{|c|}{3} & \multicolumn{2}{|c|}{4} & \multicolumn{2}{|c|}{5} & & \\
\hline & $\mathrm{n}$ & $\%$ & $\mathrm{n}$ & $\%$ & $n$ & $\%$ & $\mathrm{n}$ & $\%$ & $\mathrm{n}$ & $\%$ & $\mathrm{M}$ & $S D$ \\
\hline $\begin{array}{l}\text { 1. It is a useful means to } \\
\text { get the job done and } \\
\text { communicate. }\end{array}$ & 1 & 1.8 & 4 & 7.0 & 4 & 7.0 & 38 & 67 & 10 & 18 & 3.9 & .83 \\
\hline $\begin{array}{l}\text { 4. It displays a distinct } \\
\text { multicultural identity } \\
\text { such as my identity as a } \\
\text { highly educated doctor } \\
\text { or a nurse and my } \\
\text { identity as an Arab. }\end{array}$ & 4 & 7.0 & 16 & 28.1 & 11 & 19.3 & 19 & 33.3 & 7 & 12.3 & 3.16 & 1.2 \\
\hline $\begin{array}{l}\text { 5. is a way to show } \\
\text { solidarity with culture } \\
\text { such as my solidarity } \\
\text { with the Islamic or the } \\
\text { Saudi culture. }\end{array}$ & 4 & 7.0 & 23 & 40.4 & 7 & 12.3 & 18 & 31.6 & 5 & 8.8 & 2.95 & 1.2 \\
\hline $\begin{array}{l}\text { Positive attitude } \\
\text { variable }\end{array}$ & & & & & & & & & & & 3.3 & 0.80052 \\
\hline
\end{tabular}

\section{Statistical Tests for Negative Attitudes}

The mean of all the negative attitude variables combined was 2.5 on the 5-

point scale. This means that few participants expressed negative attitudes toward CS in the hospital. The details of the means of each variable are presented in Table 5. The results showed that $59 \%$ of the responses for the first item were "strongly disagree" and "disagree." That item was, "It is a sign of incomplete linguistic competence." Those responses were $65 \%$ for the second item, "It annoys me when people switch between Arabic and English in my presence because I cannot understand them." This shows that there was a high level of rejection for negative attitudes toward switching from Arabic to English in the general hospital.

Table 3 Negative attitudes toward switching between Arabic and English.

\begin{tabular}{|c|c|c|c|c|c|c|c|c|c|c|c|c|}
\hline \multirow{3}{*}{ Code } & \multicolumn{2}{|c|}{$\begin{array}{l}\text { Strongly } \\
\text { disagree }\end{array}$} & \multicolumn{2}{|c|}{ Disagree } & \multicolumn{2}{|c|}{ Neutral } & \multicolumn{2}{|c|}{ Agree } & \multicolumn{2}{|c|}{$\begin{array}{c}\text { Strongly } \\
\text { agree }\end{array}$} & & \\
\hline & \multicolumn{2}{|c|}{1} & \multicolumn{2}{|c|}{2} & \multicolumn{2}{|c|}{3} & \multicolumn{2}{|c|}{4} & \multicolumn{2}{|c|}{5} & & \\
\hline & $\mathrm{n}$ & $\%$ & $\mathrm{n}$ & $\%$ & $\mathrm{n}$ & $\%$ & $\mathrm{n}$ & $\%$ & $\mathrm{n}$ & $\%$ & Mea & $S D$ \\
\hline
\end{tabular}




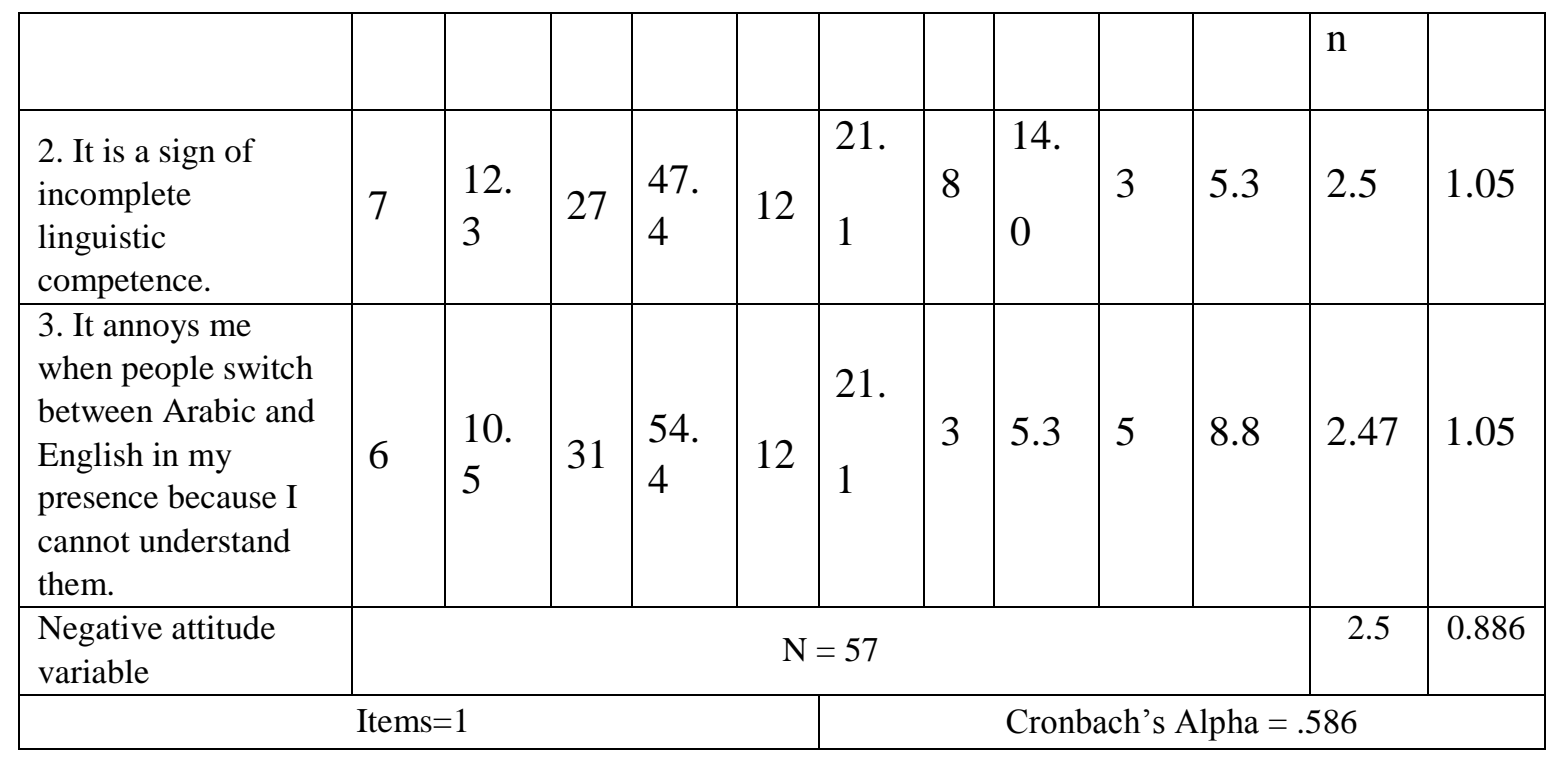

According to Friedman's chi-square test, there was no significant order of difference for these two negative attitude variables, $\chi^{2}(1)=0.391$. The $p$ value was much higher than that level of significant noted above $(p=.532)$. Even though there was no significant order of difference between the two variables, variable no. 2 had a higher mean than variable no.1 according to the mean and calculation of percentages $(\mathrm{M}=2.5, S D=1.05)$. This means that most participants rejected negative attitudes toward CS because it annoyed them when they did not understand the switched language. As for the results for positive attitudes, a number of studies reported that their subjects rejected negative attitudes (Al-Qahtani, 2014; Al Matarneh, 2011; Alhamami, 2019; Alkhawaldeh, 2019; Asmari, 2014; Hleihil, 2001; Omar \& Ilyas, 2018; Shuchi \& Islam, 2016).

\section{Statistical Tests of the Difference for Social Variables}

\section{Nationality (Linguistic Background)}

The comparison of the nationalities of hospital workers showed there was a significant difference between nationalities in the positive attitudes $(\mathrm{P}=0.054)$. This means that the nationality influence the positive attitudes towards CS. It seems that Filipino and Indian medical staff members expressed more positive attitudes ( $M=4.0$, 
$M=3.6)$ than their Saudi counterparts $(M=3.2)$. One explanation could be that the Filipino and Indian nurses liked to use their ability to speak Arabic with patients or to be nice to the patients. The influence of nationality and linguistic background was also reported in the literature. For example, Al-Qahtani (2014) reported that foreign faculty members expressed positive attitudes toward CS for socializing outside the classroom environment. However, the Arab foreign faculty members expressed negative attitudes toward CS for socializing, especially, with other Arab members. Similarly, both Alhamami (2019) and Almathkuri (2017) reported that foreign medical staff members expressed different attitudes toward CS than their Arab colleagues.

Table 4 Nationality differences in the two dimensions

\begin{tabular}{|c|c|c|c|}
\hline Nationality & & Positive attitudes & Negative attitudes \\
\hline \multirow{3}{*}{ Filipino } & Mean & 4.0000 & 2.0000 \\
\hline & $\mathrm{n}$ & 7 & 7 \\
\hline & $S D$ & .66667 & .00000 \\
\hline \multirow{3}{*}{ Indians } & Mean & 3.6667 & 2.0000 \\
\hline & $\mathrm{n}$ & 2 & 2 \\
\hline & $S D$ & .47140 & .00000 \\
\hline \multirow{3}{*}{ Saudi } & Mean & 3.2482 & 2.6277 \\
\hline & $\mathrm{n}$ & 47 & 47 \\
\hline & $S D$ & .78472 & .91763 \\
\hline \multirow{3}{*}{ Total } & Mean & 3.3571 & 2.5268 \\
\hline & $\mathrm{n}$ & 56 & 56 \\
\hline & $S D$ & .79609 & .87084 \\
\hline ANOVA & $\mathrm{F}$ & 3.092 & 2.036 \\
\hline Sig. of F (P) & $\begin{array}{l}\text { Significant } \\
\text { difference }\end{array}$ & $0.054^{*}$ & 0.141 \\
\hline
\end{tabular}

\section{Gender}

The comparison of the genders of hospital workers showed there was a significant difference between nationalities in the positive attitudes $(\mathrm{P}=0.002)$. This showed that positive attitudes toward switching between Arabic-English in 
conversations were different for the two genders. Females had the higher mean (3.58). For negative attitudes, there was no significant difference between females and males (the significance level was .357). This means that gender influences the attitudes toward CS, i.e., females expressed more positive attitudes toward switching. Similar results for the gender variable were reported by Omar and Ilyas (2018) who discovered that female participants expressed more positive attitudes toward CS and switched more generously than male participants when posting on Twitter or Facebook.

Table 5 Gender differences in the two dimensions

\begin{tabular}{|c|c|c|c|}
\hline \multirow{2}{*}{ Gender } & & Positive attitudes & Negative attitudes \\
\hline \multirow{2}{*}{ Female } & Mean & 3.5833 & 2.5833 \\
\cline { 2 - 4 } & $\mathrm{n}$ & 36 & 36 \\
\cline { 2 - 4 } & $S D$ & 0.70991 & 0.86603 \\
\hline \multirow{2}{*}{ Male } & Mean & 2.9206 & 2.3571 \\
\cline { 2 - 4 } & $\mathrm{n}$ & 21 & 21 \\
\cline { 2 - 4 } & SD & 0.78814 & 0.92389 \\
\hline \multirow{2}{*}{ Total } & Mean & 0.78814 & 0.92389 \\
\cline { 2 - 4 } & $S D$ & 3.3392 & 2.5000 \\
\cline { 2 - 4 } & $\mathrm{n}$ & 57 & 57 \\
\hline Independent Samples Test & t-test & 3.264 & 0.928 \\
\hline \multirow{2}{*}{ Sig. } & Significant & 0.002 & 0.357 \\
\hline
\end{tabular}

Age

The comparison of the age groups of the staff members showed no significant difference. This means we cannot generalize the results. However, we can use the results to our benefit as scientific indicators. According to the means and standard deviations in Table 8 , it can be said that "age" was an influential social variable. The older the person, the more positive the attitude of that person toward code-switching. Conversely, the results for the negative attitudes were not as neat. From the mean of the age category with low or moderate standard deviation, it can be said that rejecting 
negative attitudes became more intense as the member got older, but the intensity of the rejection declined and became more neutral again when they reached retirement age (More than 50). Age as a variable that affects attitudes toward CS was reported by Omar and Ilyas (2018). According to this study, the younger participants expressed more positive attitudes. Dewaele and Wei (2014) noted that senior age groups (in their 60s) expressed less positive attitude than those younger than 60 (40s and 30s). This might be attributed to changes in their work environment.

Table 6 Age differences in the two dimensions

\begin{tabular}{|c|c|c|c|}
\hline Age & & Positive attitudes & Negative attitudes \\
\hline \multirow[t]{3}{*}{$20-25$ years } & Mean & 3.1333 & 2.1000 \\
\hline & $\mathrm{N}$ & 5 & 5 \\
\hline & $S D$ & 0.96032 & 1.14018 \\
\hline \multirow[t]{3}{*}{ 25-30 years } & Mean & 3.0000 & 2.6471 \\
\hline & $\mathrm{N}$ & 17 & 17 \\
\hline & $S D$ & 0.80795 & 0.84344 \\
\hline \multirow[t]{3}{*}{$30-40$ years } & Mean & 3.4928 & 2.2826 \\
\hline & $\mathrm{N}$ & 23 & 23 \\
\hline & $S D$ & 0.74447 & 0.58048 \\
\hline \multirow[t]{3}{*}{$40-50$ years } & Mean & 3.6111 & 3.1667 \\
\hline & $\mathrm{N}$ & 6 & 6 \\
\hline & $S D$ & 0.77220 & 1.36626 \\
\hline \multirow[t]{3}{*}{ More than 50} & Mean & 3.6111 & 2.5833 \\
\hline & $\mathrm{N}$ & 6 & 6 \\
\hline & $S D$ & 0.77220 & 1.06849 \\
\hline \multirow{3}{*}{ Total } & Mean & 3.3392 & 2.5000 \\
\hline & $\mathrm{N}$ & 57 & 57 \\
\hline & $S D$ & 0.80052 & 0.88641 \\
\hline ANOVA & $\mathrm{F}$ & 1.448 & 1.653 \\
\hline Sig. of F & Significant difference & 0.231 & 0.175 \\
\hline
\end{tabular}

\section{Social Status}

The comparison of the social status (job categories) of the members revealed that there was no significant difference between social statuses. This means we cannot generalize the results. However, we can use the results to our benefit as scientific 
indicators. According to the means and standard deviations in Table 9, it can be said that the respondents' social status influenced their attitudes toward code-switching. The higher the status the more neutral a member was toward the phenomenon. The lowest were doctors with a mean of 3.1, while the mean for nurses and lab specialist was 3.5. The rejection of negative attitudes toward CS intensified as the status declined. So, nurses agreed to the rejection with a mean of 2.1 , while doctors were more neutral at $\mathrm{M}=2.6$. It should be noted that lab specialist technicians also reported levels of rejecting negative attitudes with a mean of 2.6. This might be attributed to their working environment, which prevents some medical staff members from interacting with outsiders like patients or visitors. Nurses, on the other hand, interact with visitors and patients more than the other job categories, so they were more likely to engage with people who cannot speak English. The influence of a person's social status on his attitudes toward CS was reported by Alhamami (2019) where patients reported negative attitudes toward CS while most of the medical staff reported positive attitudes toward it.

Table 7 Social status differences in the two dimensions

\begin{tabular}{|c|c|c|c|}
\hline \multirow{2}{*}{ Social Status } & & Positive attitudes & Negative attitudes \\
\hline \multirow{3}{*}{ AHP (lab specialist/tech) } & Mean & 3.5238 & 2.6429 \\
\cline { 2 - 4 } & $\mathrm{N}$ & 14 & 14 \\
\cline { 2 - 4 } & $S D$ & .51829 & 0.63332 \\
\hline \multirow{3}{*}{ Doctor } & Mean & 3.1111 & 2.6481 \\
\cline { 2 - 4 } & $\mathrm{N}$ & 27 & 27 \\
\cline { 2 - 4 } & $\mathrm{SD}$ & 0.89156 & 1.10779 \\
\hline \multirow{3}{*}{ Nurse } & Mean & 3.5625 & 2.1250 \\
\cline { 2 - 4 } & $\mathrm{n}$ & 16 & 16 \\
\cline { 2 - 4 } & $S D$ & 0.77669 & 2.5000 \\
\hline \multirow{2}{*}{ Total } & Mean & 3.3392 & 0.5000 \\
\hline
\end{tabular}




\begin{tabular}{|c|c|c|c|}
\hline & $\mathrm{n}$ & 57 & 57 \\
\cline { 2 - 4 } & $\mathrm{SD}$ & 0.80052 & 0.88641 \\
\hline ANOVA & $\mathrm{F}$ & 2.179 & 2.067 \\
\hline Sig. of F & $\begin{array}{c}\text { Significant } \\
\text { difference }\end{array}$ & 0.123 & 0.137 \\
\hline
\end{tabular}

In conclusion, the results of the qualitative analysis revealed that most of the Arab medical staff had positive attitudes toward code-switching at the hospital. However, a few Arab members expressed neutral attitudes, and one foreign member expressed a negative attitude toward CS in the hospital. The prevalence of positive attitudes among the medical staff members was also supported by the results of the questionnaire. The predominance of positive attitudes toward CS in professional contexts also was reported in the literature. For example, some studies in academic contexts reported that more participants expressed positive attitudes toward CS in the classrooms than those who expressed negative attitudes (Al-Qahtani, 2014; Alkhawaldeh, 2019; Almohaimeed \& Almurshed, 2018; Asmari, 2014). In workplace contexts, both Al Matarneh (2011) and Hleihil (2001) reported that Jordanian workers expressed positive attitudes more than negative attitudes toward CS in urban cities of Jordan. Finally, in the medical context, Alhamami (2019) reported that positive attitudes were more common than negative attitudes toward using CS in hospitals in Saudi Arabia.

Moreover, the results of the interviews showed that the two most influential factors were the social status, and nationality (linguistic background). The influence of nationality (linguistic background) and social status were also reported in the results of the questionnaire. Age and gender were not seen as significantly influential in the interviews; both young and senior and male and female members expressed similar attitudes toward CS. However, the quantitative data did report gender as an influential factor. This difference might be attributed to the size and variety of the 
sample, which included senior members of the medical staff. Although the female members expressed more positive attitudes toward CS in the hospital, the male members rejected negative attitudes, and they expressed above-average positive attitudes. Thus, it can be said that both genders expressed positive attitudes toward the phenomenon. The influence of those social factors was reported in the literature (e.g., Al-Qahtani, 2014; Alhamami, 2019; Asmari, 2014; Hleihil, 2001; Omar \& Ilyas, 2018; Shuchi \& Islam, 2016).

\section{Research Limitations and Recommendations}

The findings of this study must be seen in the light of some limitations. First, the study was limited in its regional scope of investigation, because of limited time and resources. It was restricted to the city of Riyadh, which is one of thirteen regions in SA. Generalizing the results of the study might be possible based on the central location of the capital and country's inclusiveness of multicultural values.

Nevertheless, it would be interesting to extend the study to the other regions and arrive at more extensive results. Moreover, the study was focused on Arabic-English $\mathrm{CS}$ as it is the most common forms of CS in the healthcare sector. Other researchers are encouraged to take the study further and investigate the other varieties of CS in the healthcare sector.

Every study is limited in its methodology. In this study, the sample of the study was selected purposefully. This might have injected a measure of bias from the researcher's judgment and make it difficult to generalize the results. Nevertheless, this effect of judgment could be mitigated when the selection of participation is based on an identified category such as homogeneity (Dörnyei, 2007). However, this method of sampling can be very effective in saving time in studies that explore anthropological contexts that tend to consume such resources (Hoffman, 2014). 


\section{Research Implications}

This study has pedagogical and hospital administrative implications. The pedagogical implications involve approaches for teaching English as a foreign language and Arabic as a second language. The study showed how foreign members of the staff who did not speak Arabic faced communication breakdowns because of their weak proficiency in Arabic - despite the assumption that English is the lingua franca of medical contexts. It seems there is a need to prepare foreign medical staff members with basic Arabic skills and familiarity with Saudi cultural norms so they can function appropriately and build healthy relationships with their colleagues and patients. Conversely, the study showed that Arab members of the medical staff must have English language skills for social purposes. Although most of the medical staff spoke medical English, some were not adept enough as English speakers to socialize and communicate with their foreign colleagues. Understanding where and why both Arab and foreign members switch codes helps course designers in providing them with language courses tailored to their needs. Medical staff members should be equipped with both Arabic and English language proficiency in order to function accurately in sensitive medical situations.

Moreover, this understanding of the attitudes toward CS might help hospital leaders to develop a realistic language policy that accounts for the linguistic needs of the staff and visitors. For example, it can include Arabic along with English to be languages spoken for communication among the medical staff in order to account for non- proficient English speakers. Both English and Arabic speakers on the medical staff must be available at the counters at all times to serve visitors who do not speak one of the two languages. 
Finally, this study showed that attitudes towards CS is influenced by other social factors, not only linguistic proficiency. Factors like the participants' social status and linguistic background, influence the medical staff attitude towards code switching between Arabic and English. This study proposed a mixed method of investigating CS between Arabic and English in hospitals. It can be used by other researchers to investigate the phenomenon.

\section{References}

AbdulSalam, A., Elsegaey, I., Khraif, R., \& Al-Mutairi, A. (2014). Population distribution and household conditions in Saudi Arabia: Reflections from the 2010 census. SpringerPlus, 3(1), 530. https://doi.org/10.1186/2193-1801-3-530

Al-Khatib, M. a, \& Sabbah, E. H. (2008). Language Choice in Mobile Text Messages among Jordanian University Students. SKY Journal of Linguistics, 21(Crystal 2001), 37-65.

Al-Qahtani, A. (2014). The phenomenon of code-switching and code-mixing as practiced among faculty members in a Saudi University. Language Phenomena 
in Urban Society, 1-8. https://doi.org/10.13140/RG.2.1.3143.1122

Al Heeti, N., \& Al Abdely, A. (2016). Types and functions of code-switching in the English language used by Iraqi doctors in formal settings. International Journal of Advanced Research and Review, 1(8), 10-18.

Al Matarneh, Y. (2011). Code-Switching between Arabic and English in the apeech of aviation field personnel at Amman Civil Airport. Mutah University.

Alenezi, M. Q. (2016). Gender and Students’ Attitude toward Code-Switching: A Correlational Study with Reference to Saudi Arabian Medical Students at Northern Boarder University. International Journal of English Language \& Translation Studies, 4(3), 154-166.

Alhamami, M. (2019). Switching of language varieties in Saudi multilingual hospitals: Insiders' experiences. Journal of Multilingual and Multicultural Development, O(0), 1-15. https://doi.org/10.1080/01434632.2019.1606227

Alhassoun, L. (2014). English-Arabic Code-Switching among EFL Female Students at Al-Imam Muhammad Ibn Saud Islamic University. Al-Imam Muhammad Ibn Saud Islamic University.

Alkhawaldeh, A. (2019). Code-switching between Arabic and English : Reasons, types and attitudes as expressed by EFL female students at Imam Muhammad Ibn Saud Islamic University. International Journal of English Linguistics, 9(6), 135-147. https://doi.org/10.5539/ijel.v9n6p135

Almathkuri, J. (2017). Investigating the motivation behind language alternation at KASH in Saudi Arabia. University of Southampton, School of Humanities.

Almohaimeed, M. S., \& Almurshed, H. M. (2018a). Foreign Language Learners' Attitudes and Perceptions of L1 Use in L2 Classroom. Arab World English Journal (AWEJ), 9(4), 433-446. 
https://doi.org/https://dx.doi.org/10.24093/awej/vol9no4.32

Almohaimeed, M. S., \& Almurshed, H. M. (2018b). Foreign Language Learners' Attitudes and Perceptions of L1 Use in L2 Classroom. Arab World English Journal (AWEJ, 9(4), 433-446. https://doi.org/10.24093/awej/vol9no4.32

Asmari, A. Al. (2014). Teachers' perceptions about the use of mother tongue in Saudi EFL university classrooms: A gender-line investigation. Theory and Practice in Language Studies, 4(10), 2066-2075. https://doi.org/10.4304/tpls.4.10.20662075

Belaskri, K. (2017). The Linguistic Gap in Doctor-Patient Communication in Algeria. Lublin Studies in Modern Languages and Literature, 41(2), 1-11.

Bullock, B. E., \& Toribio, A. J. (2009). Themes in the study of code-switching. In B. E. Bullock \& A. J. Toribio (Eds.), The Cambridge Handbook of Linguistic Codeswitching (pp. 1-19). Cambridge: Cambridge University Press.

Canagarajah, S. (2011). Translanguaging in the classroom: Emerging issues for research and pedagogy. Applied Linguistics Review, 2, 1-28.

De Socarraz-Novoa, A. (2015). Code-Switching in a Multilingual Workplace. Journal for Undergraduate Ethnography, 5(1), 1-8. https://doi.org/10.15273/jue.v5i1.8261

Dewaele, J. M., \& Wei, L. (2014). Attitudes towards code-switching among adult mono- and multilingual language users. Journal of Multilingual and Multicultural Development, 35(3), 235-251. https://doi.org/10.1080/01434632.2013.859687

Dörnyei, Z. (2007). Research methods in applied linguistics: Quantitative, qualitative, and mixed methodologies. Oxford: Oxford University Press.

Garrett, P. (2010). Attitudes to language. Cambridge: Cambridge University Press. 